\title{
Socio-cultural disadvantages and cumulative deficits: which education can fight in- equalities?
}

Desventajas socioculturales y déficits acumulados: ¿qué educación puede combatir las desigualdades?

\section{ABSTRACT}

This article focuses on identifying the root causes of educational problems before starting "educational treatment" It starts from the premise that prevention is better than cure since it avoids further damage and is a way to prevent the problem from getting worse. Prevention understood as early action, which takes advantage of adequate planning and programming processes, keeps us away from the dangers of school failure, and guarantees us "cultural health". Through a contrasted and comparative methodology, it was possible to analyze and interpret the sources that inform a review of the literature, with the objective of understanding how students should be helped at an early stage if they do not have the necessary conditions to face their path of acquisition. The aim is to prevent teachers from "returning" responsibilities once the damage is done, by compensating and treating the "deficit" and creating favorable conditions before starting the new segment of education. The article addresses these problems by trying to focus attention on the cumulative capacity of the "difficulty" to consolidate and grow, making subsequent compensatory interventions more problematic in their effects.

Keywords: Education; cumulative deficit; educational interventions; inequity

\section{RESUMEN}

Este artículo se centra en la identificación de las causas fundamentales de los problemas educativos antes de iniciar el "tratamiento educativo". Se parte de la premisa que es mejor prevenir que curar, ya que evita los daños posteriores y es una forma de evitar que el problema empeore. La prevención entendida como acción temprana, que aprovecha los procesos adecuados de planificación y programación, nos mantiene alejados de los peligros del fracaso escolar y nos garantiza una "salud cultural plena". A través de una metodología contrastada y comparativa, fue posible analizar e interpretar las fuentes que informan una revisión de la literatura, con el objetivo de entender cómo se debe ayudar a los estudiantes en una etapa temprana si no tienen las condiciones necesarias para enfrentar su camino de adquisición. Se intenta evitar que los profesores "devuelvan" las responsabilidades una vez que el daño está hecho, compensando y tratando el "déficit" y creando condiciones favorables antes de iniciar el nuevo segmento de la educación. El artículo aborda estos problemas tratando de centrar la atención en la capacidad acumulativa de la "dificultad" para consolidarse y crecer, haciendo que las posteriores intervenciones compensatorias sean más problemáticas en sus efectos.

Palabras clave: Educación; déficits acumulados; intervenciones educativas; falta de equidad 


\section{INTRODUCTION}

When it comes to providing equal opportunities for individuals, developing appropriate curricula, strong cultural profiles, etc., it is primarily intended to emphasize the importance of establishing a culture of inclusion in education capable of marginalizing injustice and discrimination, positively stimulating all students to learn, especially the weakest ones, so that they are respected in their particularities (Booth \& Ainscow, 1998), in their acquisition processes and in their needs. This culture implies that it is not sufficient for a pupil to be placed in a context of favorable education in which he can build positive relationships with peers and teachers, but that it must be possible to do so by allowing him to feel socially included, thus avoiding exposing him to negative situations of failure, disaffection with learning or poorly meaningful. However, when it speaks about issues related to obstacles or disadvantages in education, theories, models, and research mainly focus on students with disabilities, without looking at other types of subjects, whose difficulties are related to equally important dimensions of existence, such as socio-economic, cultural, ethnic, gender, social and so on. This is all the clearer when looking at the industry literature, which has now become classic, relating to learning problems not necessarily attributable to disability (Dean, 1989; Haug, 1998), but aimed at considering forms of disadvantage that could be defined as "thin" and which still remain closely interrelated, directly or indirectly, to school results (Bakken, 2003; Coleman et al., 1966; Croll, 2004).

In fact, there is an extensive repertoire of knowledge concerning cumulative educational deficits, but educational research on inclusion and social inequalities has not always been adequately deepened and should, on the contrary, be taken into account if precise educational phenomena of iniquity or when it comes to basic literacy are to be explained. In particular, the latter, if not appropriate, may succeed in undermining both the prospects for development and growth of the individual and those of literacy as a whole, negatively affecting school success (Welsh, Parke, Widaman, \& O'Neil, 2001) and the future life of each child. Research tends to show how literacy, cultural and social skills are intimately correlated (Bursuck \& Asher, 1986; Kupersmidt, Coie, \& Dodge, 1990) to school success and the emergence or otherwise of forms of exclusion (Wentzel, 1993) at different levels. The case of language skills is emblematic in this sense. As cross-cutting, they are considered key competencies of education, even when they strictly relate to the vehicular language of teaching. These kinds of skills continue, after a long time, to remain the subject of a wide and intense debate on cultural disparities, since they are still strongly related to socio-cultural variables, socio-economic status, social inclusion, and so on (Bryant, Burchinal, Lau, \& Sparling, 1994; Stipek \& Ryan, 1997), establishing the basis of the widening of new alphabetic divas, double exclusions or combinations of inequalities of a different nature.

The contribution has three objectives. The first objective of the contribution is to provide a brief insight into how social conditions and cultural characteristics can shape the risk of failure and affect the overall well-being of the individual, focusing attention on the importance that the cumulative deficit assumes in relation to the processes of teaching-learning and connoting the emergence of a model in which a kind of "reserve population" is stratified, that is, of a group of individuals who do not possess the cultural tools that allow them to live and work.

The second objective is to understand the importance of the risk of being exposed to the cumulative deficit in school settings. It means reflecting on adverse cultural and social conditions to take this into account when drawing up the educational proposal and creating conditions conducive to learning. The extensive repertoire of research that examined the influence of specific cultural characteristics, such as social resources, which can affect learning in the context of "chronic situations" of disadvantage, is now well established. Although access to education and the assumption of precise learning behaviours, therefore contribute greatly to determining the "cultural health" of individuals, it is appropriate to explicitly focus on contextual cultural factors and processes that can shape the cumulative deficit and alphabetical disadvantage to prevent them from reproducing incessantly, even in an intergenerational sense. In this contribution, it was therefore considered essential to highlight these reports in-depth for a better understanding of the nature of cumulative deficits, which are established over time in education and which risk undermining the processes of acquiring pupils as a whole, their well-being, and their professional future.

A third and further aim was to look, from a point of view of prevention of interventions, at cumulative 
deficits as possible risk factors for cultural and social exclusion.

\subsection{The problem: disadvantages and "culltural damage"}

Education develops skills that help people gain control of their lives, encouraging and enabling a direct relationship with reality. The consequences of the lack of equity in education, such as the way governments mobilize, allocate and manage the investment in education, and the precariousness of learning conditions in terms of poorly trained teaching staff, inadequate teaching resources and structures, etc., have a major impact on the efficiency of the school system as a whole and on the teaching-learning processes in micro contexts, tending to accumulate at many levels, from socio-economic and behavioral to physical. Some of these dysfunctions create real deficits of different nature that stratify and influence each other over time. In particular, for example, a low sense of control over one's own life accelerates the cultural and sometimes even physical damage, which in turn diminishes the sense of control itself, as well as the affective willingness to learn and the scholastic concept of self that contaminates an individual's general self, extending negative action outside of school. In fact, it often happens that education progressively focuses on good cognitive functioning and a strong sense of personal control in the best students, inducing a sense of helplessness in the weaker ones and thus creating great cultural differences that could produce negative effects over time, which may or may not diminish or thin out over time as people adapt to contexts, circumstances, tastes and times, or increase or decrease the enthusiasm of the subjects towards learning, which intensifies or decreases with respect to the quality and significance of experiences.

The cumulative deficit hypothesis suggests that growth and developmental difficulties in children will increase in conditions of marked social and environmental deprivation as they grow, if not properly sustained, and that this hypothesis will also affect the negative effects of education, which will tend to increase as the difficulties arise and are not compensated for. Sometimes, the initial disadvantage also ends up inducing people to be treated unfairly at school, and this is usual in contexts where the flexibility of a teacher's expectations is evoked precisely when a student is perceived as incompetent. Being alphabetically poor is, therefore, more than a "matter of income", so much so that it is possible to experience forms of disadvantage at different levels and at different levels, involving various dimensions of life, such as, for example, access to resources and possibilities and so on. Thus, the cumulative deficit at school refers to poorly advantageous processes, which cause the production or reproduction of problems in pupils at school with the result of becoming more and more consistent over time and turning education into a sounding board for "iniquity". This is due to the fact that education and education are not neutral processes and transform the individual, playing a pivotal role in his or her learning path and putting his or her life on a different path, as the main axes on which rests the greatest weight of success. Much of success in life depends in fact on the quality of the educational and educational processes, which originate from and within the school, but which can also undermine its function. It is in order to fully understand the impact of education on the individual, cultural and social heritage of an individual that it is essential to think about how it can bring visible and invisible benefits throughout life.

In fact, although it is true that at the beginning of the training course minimal and imperceptible are almost always the difficulties that manifest themselves, it is equally true how they cumulate and combine over time, producing delays and increasingly large differences between people with the same or different levels of education. If it is true that one never goes back culturally, it is equally true that one can also be exposed to forms of alphabetical loss, just as happens to the adult population affected by forms of return or functional illiteracy, or even by forms of alphabetical risk that configure inappropriate conceptions such as those that see the elderly treated as a real "super-adult". Much has been written about the ways in which the advantages and disadvantages of early childhood persist at a late age and survive despite the many contingencies and random or not random life events that occur during it and during school. More than the attenuation overtime of the first disadvantages (Crystal \& Shea, 1990; Crystal, Shea, \& Reyes, 2017), it is the amplification that causes different gender effects to be observed. Let's think, for example, how, during an individual's career, the most advantaged and educated one differs markedly in terms of the use of more opportunities for skills growth over time and benefits that come later; the individual with a lower level of education is in fact much less likely to experience forms of dissatisfaction and work inadequacy within fifty years (Crystal \& Shea, 2003) and is more exposed to further inequalities in advanced life. From the economic to the cognitive level, the differences that affect culture continue to grow during the existence 
of every man and the accumulation of cultural disadvantage is able to affect aspects that go beyond the boundaries of "cognitive" to evolve even in forms of psychosocial stress that affect his overall well-being. Therefore, the exposure to cultural disadvantage permeates the overall emotional, cognitive, and physical health of individuals, as well as their family relationships, peers, etc., and not only the success at school, extending the possibility of increasing negative results.

The cumulative disadvantage can therefore be considered emblematic from the point of view of "chronic" inequalities in the educational and developmental contexts of children and young people and their transitions into adulthood, which lead to phenomena such as dropout, Early School Leavers (ESL), etc. (Nuzzaci \& Marcozzi, 2019; 2020). Factors such as low parental education, low family income, family structure, ethnic minority, immigrant status, etc., are not, for example, simply inducers of individual disadvantages, but show to have additive effects on an individual's chances of existence. Research in this regard shows that they are important to be assessed in a wide range of service settings for children and young people and not only in the areas of education, such as medical care, family service, mental health, and employment. However, it is now well known that schools should primarily address the "cultural health" of young people, aiming at taking on the highly cumulative disadvantage and employing proactive forms of design and assessment, able to stem and contain the difficulties, taking early preventive and corrective measures, potentially transversal, to cascade the possible alphabetical disadvantages that could be produced and to stem the unfavorable conditions for learning. In order this means to increase educational opportunities and break the negative deterministic chains that close the teaching-learning processes to dead ends, moving them instead towards progressive positive cultural adaptations.

Children and young people who encounter "cultural adversity" succeed better when didactically one turns to help them build in them a learning-friendly willingness and good coping skills when one tends to offer them adequate cognitive, social and affective-relational support to advance their visions, their <perceptions and goals (Jaffee et al., 2007), as well as their future beliefs about their school self, which induce a greater psychosocial adaptation and a greater ability to cope with the stress related to the most difficult school learning. In addition, the ability to assess their competence in less coercive ways with forms of educational diagnostic evaluation less related to the regulatory aspect, combined with positive future prospects, allows to mitigate the negative effects of exposure to the deficit, not only cognitive but also on the emotional level. In this sense, with regard to the variations in cultural damage over time, it's thought that it the importance of the quality of educational responses provided at different levels, which can guide the compensation and divergence of interventions through the permeation of broad-spectrum benefits:

- the accumulation of the alphabetical deficit (sum of the cumulative deficits over time);

- amplification (negative consequences that become stronger over time);

- integration (negative consequences that reinforce each other).

In education, the use of appropriate strategies provides promising evidence. Such use serves to contain the negative factors related to alphabetical processes in the regulation of negative emotions with respect to the acquisition of central skills while maintaining a focus on the usefulness of future learning: mitigating the effects, thus favoring the functioning of skills that can be developed, applied and transferred to different contexts becomes an indispensable approach. Of course, teaching practices related to forms of inequality have been well analyzed by the literature and connected to models of individualization and personalization, which did not claim to be exhaustive but rather to start the first step towards a better fulfillment of the educational objectives by all students and to build education "to measure" them (Claparede, 1920). From these assumptions, the new management of school activity and greater autonomy was born over time, which allowed the realization of more flexible, reactive, innovative, and proactive teaching with a "compensatory" character of the founding acquisitive elements. 
The issue refers to the skills for the management of the situations of the teaching-learning processes in reference to:

- the nature of the tasks, the mastery of skills and knowledge and their inscription in a continuous progression;

- the quality of the task in the sequence and its level of cognitive activation;

- the accomplishment of the task and the mediating effect of the teacher and peers.

From the point of view of didactic communication, one can

- the ways of communication;

- strategies to enable students to activate actions, experiences and expertise;

- the ways as reduction of the scarce symmetric relationship between teacher-student and peers to make a real accompaniment of the students.

All the intentional and systematic activities, which respond to learning needs and involve an organized and sustainable communication aimed at stimulating learning, mark the perimeter of an effective education, which brings with it forms of intervention aimed at producing permanent and lasting acquisitions characterized by effective actions that require, through the use of a number of material means, the achievement of vital objectives clearly explained. The important thing is the criterion for the composition of the formal framework in which the teaching and learning processes are organized. The latter include any improvement in behavior, information, knowledge. At the same time, however, the work on "class effects" or "social and cultural effects" has demonstrated the existence of more complex mechanisms that resist precisely defined typologies.

Classrooms are the places where a set of skills and attitudes are built that strengthen the resources, visions, and interpretations of the students. There is, therefore, a real strength of the school to help those who present the greatest difficulties, which, if not promptly stopped, are likely to chronically alter aspects of development and to interfere with the regulation of emotions, cognitive skills, adaptive skills of acquisitions and identification of alphabetical goals, as well as obviously on cognitive, affective-relational, social and psycho-motor learning, in short, on the overall "cultural health" of the individual. There is, therefore, a real ability of the school to help "chronically weak" students to come out of cumulative disadvantage by offering them resilient perspectives and providing them with guidance to overcome the impact mechanisms of the difficulty, better clarifying how objectives are identified and risks are accumulated, producing real quality in the learning pathways and activating in them the use of internal resources to deal with what is produced externally.

However, it is clear that the intersection between educational inequalities and cultural deficits is an important link both for the proliferation of inequalities and for the intervention aimed at improving the quality of training. Research indicates that certain benefits of education could be greater precisely for those pupils who have fewer resources in other areas, including family areas (Ross \& Mirowsky, 2011), if the school could act as a "buffer effect", allowing them to "break cultural isolation".

The inadequate and blunt trajectories in education lead to additional threats in the old age through the greater proliferation of inappropriate behaviors and attitudes, which do not always concern only the alphabetical dimension. The same goes for the use of "impoverished" cultural resources in education processes, which risks distributing alphabetical skills unequally on the basis of belonging to social status, minority groups, etc., which is also a threat to the development of the literacy dimension. This is a fundamental aspect to reflect on, which should encourage teachers to act "fairly" and make the school responsible for children's future in order to be able to act in the long term on some factors that are now emblematic and crystallized of social and cultural inequality. This is confirmed by important international surveys, such as those carried out by OECD-PISA, which highlight the positive role of schools and policymakers in reducing educational inequalities mainly linked to the social origin that undermines the individual's learning, well-being, and right to active citizenship. 


\section{METHODS}

This study analyzes publications collected as part of a larger systematic review that examines the effectiveness of cultural prevention and intervention programs on prerequisite outcomes. The systematic review of evidence is designed to describe the variety of risk factors that affect pupils' academic achievement and future. The study used a contrastive methodology that has helped to rebuild a contextual and conceptual framework based on a coherent and logical scheme based on different scientific points of view, which guided the choices made. It included the theoretical analysis of the body of contributions and the methods and principles associated with it.

In this article, a conceptual framework is provided for analyzing and interpreting the sources informing a review of the literature. Using, in particular, the frameworks already defined in other studies, it outlines four main types of sources that structure the research synthesis: speeches, observations, studies, research. The data analyzed were used to describe the phenomena related to the cumulative deficit. Analysis techniques were adopted which led to the synthesis of the research: constant comparison analysis, domain analysis, component analysis, and theme analysis. The framework represents a first step in helping to rigorously analyze and interpret literature.

In this article, one analyses the use of research sources to make decisions for compensation. Through a structured review of 215 research products (articles, volume contributions, and volumes) It Is explored "where", "why" and "how" these sources were used in the context of compensation decision-making. The review suggests that the methodology used has been adapted for the purposes. The review, however, identifies a number of incident factors and researchers' concerns that provide a comprehensive account of the central issues involved in reading the phenomenon.

In addition to the review of the literature, in-depth interviews were also used on subjects enrolled in the educational area degree courses in the university context of L'Aquila to explore the idea that these subjects have problems generated as a result of lack of initial compensation in the education process. An in-depth content analysis was conducted starting from a relatively small group, about 40 subjects, aged between 21 and 42 years, which allowed to put at the center of the research the point of view of the participants on this issue, which is not mentioned in this article. The interviews turned out to be an adequate method to study the idea that subjects, future teachers, have input compensation of the students and the cumulative deficit, as well as the problems related to them. In particular, the results indicate that future teachers are able to provide motivation for why the initial deficit of students in difficulty ends up becoming cumulative.

\section{DEVELOPMENT}

\subsection{The school can do a lot: the role of alphabetical processes}

In the 1960 literature focused on examining the ways in which the alphabetical processes at school were linked to the class of origin of the students, where reflections emerged on how social environments could act as a sounding board and marginalize them through a system that favored high-class skills. In this way, literacy was understood as part of a constant process of cultural recycling that served to redefine the causes of an initial disadvantage and to justify the educational "failure" with the socio-economic background highlighted through cumulative deficits that gradually stratified over time. But literacy today, after some time, is still a controversial terrain in which opportunities and difficulties intersect, which can be conceived as a space for the development of skills that affect all students, especially encourage those who are weak and silent and give them a voice. This is because the main purpose of education is to build attitudes, skills, and knowledge that transform individuals by offering them the opportunity to pursue individual, inclusive, and democratic acquisition paths, rich in networks of opportunities. For this reason, literacy still represents a concrete response to social inequalities and constitutes a challenge for education, which redraws the boundaries precisely in the new relationship between formal, informal, and non-formal learning. Unlike in the past, today schools must intervene very early, anticipate the compensation of any initial deficits, and identify cultural risks as a whole in order to establish the character of educational interventions and their value. This assumption derives the broad centrality from which the importance of pursuing significant learning in order to build a "common cultural asset". 


\section{RESULTS}

\subsection{Analyses}

The main premise of literacy, therefore, is simple: the high degree of correlation between the student's literacy difficulties and the variables linked to his or her background (family, social, etc.) must be taken into due consideration in order to support and break down specific areas of difficulty, which must be addressed when planning interventions and planning educational actions, as well as in forms of authentic evaluation. This is well summarized in the ability of the school to improve learning conditions by adopting a wide range of strategies (imitative, heuristic and creative) that promote the involvement of students in practices and activities to improve literacy. If the question of what literacy is and what literacy should understand in itself is rarely raised, since all the considerations about it are often put forward as if its meaning were obvious, the common answer can only be given by referring mainly to how it can help to avoid the subordination of certain individuals by bringing them out of their original situations of inequality. In this sense, the current debate, increasingly growing, focuses on how it is based on the skills that make the symbolic repertoires of culture accessible, starting from an analysis of:

- the variety associated with education and the characteristics of the educational recipients, in terms of diversification of the different school populations, and which has become the premise on which the teaching-learning processes are based;

- the variability of learning conditions due to the high diversification of school contexts and the difference between them;

- the integration between formal and informal learning, used as a complex filter to increase alphabetical processes, considering the differences related to the different dispositions, backgrounds, experiences, attitudes and values to which students belonging to different school groups are exposed;

- the equity that serves to overcome, precisely through alphabetical processes, to try to overcome cultural and social disparities.

When these assumptions are violated, literacy ends up having a profound effect of strengthening the relationships between results and the social status of the students, inducing them to internalize a certain sense of the uselessness of literacy practices (Heath, 1983; Taylor \& Dorsey-Gaines, 1988) both at home and at school, both on an individual and social level (and of the communities to which the students belong). And this should lead us to reflect on the degree to which a practice of literacy has or has not been embodied in our society and the implications that this has for the development of society and culture itself.

The sociocultural problem of the deficit is therefore very often explained: on the family level, in terms of families that pass through an intergenerational cycle of disadvantage, with inadequate experiences and insufficient preparation, which are transmitted from parents to children; on the level of responsibility of the individual and in his or her ability to overcome failures, breaking the intergenerational transmission of skills. Instead, it is necessary to shift the attention to a different conception that poses the question on the political level and on the inability of the system to go further and to succeed in making individuals overcome disadvantage in favor of a rebalancing of their set of skills. Literacy is not only a technical issue and the reflection on it must become part of the cultural policy of a society, from which derive answers that cannot be limited to interpret failures with phenomena from other sources, such as poverty, poor parenting skills, dysfunctional families, poor family results, aspiration and motivation and other categories of "risk".

In other words, the question of "alphabetic privilege" presents one number of problems when considering literacy as an activity that is culturally and socially appreciated by the community. The current knowledge society requires people to equip themselves with innovative cognitive and social tools to support the sudden changes to which the contemporary world exposes them. The growing range of multimodal and 
semiotic (meaning) communication channels, tools and systems extends, rather than replaces, the types of literacy previously linked to the "book" as the only vehicle for learning to include digital writing, audio elements (sound), the visual components (image), gestures (body language) and spatiality (the use of space); all these systems of signification capable of giving life to "multiple texts" based on simultaneous methods of textual processing and production aimed at constructing complex meanings. The different alphabetic needs that have rapidly emerged in recent years have therefore shifted the axis of literacy towards multiple dimensions, playing a decisive role in the synchronic and diachronic understanding of alphabetic cultures and their different expressions, especially at a time when new forms Signs, such as media, technology, etc., appear not always easy to identify and teach and where communication genres are continuously expanding through networks, tools, communities and purposes, designing new training spaces. In a moment, therefore, in which the new forms of literacy (especially media literacy) appear elusive and not always easy to identify and teach and where the genres of communication are constantly expanding through networks, tools, communities and purposes, the need to define and conceptualize the new "training spaces". At the same time, however, in the era of digital education, ancient discriminations are reborn and re-emerge that lead to new implicit misunderstandings of the representation, expression, and organization of knowledge, which, challenging the adequacy of traditional education practices, the contexts and objectives of education are questioned.

Also, in the light of what has been stated here, the idea of an educational deficit that the school has the responsibility to fill is not a trivial matter since if it is not taken into account, there is a risk that double exclusions will be affirmed. At the same time, however, rather than understanding the social origin of a pupil as a place where educational failure can occur, one could look at it as a source of influence on the educational process which, however, cannot yet be seen to exist at a distance. A strong correlation between education and income growth. From this point of view, attention to educational processes should focus on recognizing the diversity of thought, language, and worldview that belong to the real lives and experiences of children, as members of families and communities, rather than on reproduction. of a wellconstructed ideal, and on the need to give space in the curricular paths to the voices of the students to guarantee them the achievement of the educational objectives consciously.

\subsection{Inequalities, alphabetic processes and compensatory trajectories}

Paulo Freire (1970) argued that learning to read and write should be part of an overtly political process aimed at improving understanding of how and where "oppression" works and stimulating "informed engagement" to overcome it. Literacy is acquired in the process of understanding the world from a perspective that presupposes the functioning of structures of oppression, which means that the process of literacy itself and cultural action must reflect the values of equality rather than interpreting forms hierarchical and of a certain passivity. In this direction, literacy, which includes reading, writing, comprehension, calculation, is intrinsically conceived as broader, that is, as an act of reading and writing the world. This means that teaching cannot reproduce the forms of unequally distributed power within the social structure in such a way that the voices of some continue to remain marginalized while others continue to remain privileged. Therefore, the perspective of preventing the accumulation of the cumulative cultural deficit remains the way to the concrete achievement of the educational objectives by all students, just as curricula policies cannot be fully understood and evaluated without considering their implications. For the promotion of one or the other form of literacy through the activation of personalized and individualized strategies. For students who experience the effects of multiple and cumulative types of disadvantage, tailor-made and individualized interventions can provide the necessary support, especially if integrated and acting in logical continuity on multiple contexts (family, school, community), in order to exploit the combined effects of the latter to better support them. One way to do this could be to explore whether the values and practices of the family environment influenced the school and whether it was able to interpret the familiar voices and the community to which the pupils belong, as well as being able to support their cultural values. This would lead to the expansion of alphabetic functions in such a way that students from a range of unrewarding cultural experiences could be more easily and consciously helped within the classroom context. Legitimate tools for investigation, exploration, and critical awareness recognize literacy, or rather multiliteracies, as an essentially non-neutral political process, on which it is essential to focus due to the pre-eminent character it assumes when the inadequacy of its practices can limit the social participation of those who do not have full access to the dominant codes. 
The culture of the school is therefore a mosaic of influences from different cultures and forms of support that must be recovered and made explicit, i.e. visible. As Giroux (1987, p. 20) argues, this implies that students and teachers are given room to retrieve their own interpretative repertoires, so that they can tell their own stories and, in this way, control and criticize those stories that are being told. in opposition to theirs and those who have lived.

Inequalities in educational achievement are easily apparent to any parent, teacher, or politician. Unfortunately, the solutions to overcome them are less obvious. Some go so far as to say pessimistically that these kinds of inequalities cannot be overcome and that the initial disadvantage is difficult to overcome (Stanovich, 1986). This is evident in the attitudes of some teachers who tend to have a pessimistic view of the abilities of students with difficulties in recovering from manifest problems and believe that students who can do so only because of an alignment between the study practices of the child with those of the family in a coherent set of expectations and interventions. In this sense, there is a large body of literacy studies that continually show how the results obtained previously by a pupil are the strongest predictor of subsequent results (Chatterji, 2006; Duncan et al., 2007; 2011; Senechal, 2006; 2011; Senechal \& LeFevre, 2002; Storch \& Whitehurst, 2001, 2002; Xue \& Meisels, 2004).

However, inequalities in alphabetical outcomes resulting from cumulative disadvantages and specific erroneous growth trajectories can be broken because, although there is social, family, etc. factors. contributing to the achievement of full literacy, schools and teachers still plays a central role in recovering from initial difficulties. In this case, schools can act as a place of intervention to interrupt the trajectory of cumulative disadvantage through the provision of high-quality education and effective interventions provided by methodologically competent teachers (Nuzzaci, 2016). It is precisely in response to inequalities that it appears important to adopt a multi-perspective approach according to which focusing on the quality of education becomes of the utmost importance to increase results. Indeed, it is precisely the results that suggest how some students could overcome obstacles in learning and how schools could be of great help in doing so. A complementary concern to these inequalities in performance is the low literacy levels of the population. Here the gap is between what students are supposed to achieve and what they actually achieve. Putting it another way, some stakeholders believe that the education system produces a small percentage of high achieving students, which is in stark contrast to larger groups of low achieving students, at least as measured by the International Student Assessment Program (PISA), reproducing already known normality curves. In this case, the concern is not just that some groups of students are left behind, but that so many students are too likely to be poorly competent (Darling-Hammond \& Rothman, 2015).

Concern about low literacy levels has grown more pronounced over the past fifty years as cultural goals have changed. Historically, only high levels of literacy were expected from the elite, while low levels were sufficient for the rest of the population (Resnick \& Resnick, 1977). However, with time and with social changes, the demand for literacy has increased as has the recognition of the importance of full literacy for the entire population; the rise of the information age has made this goal even more imperative. It is in fact widely recognized that participation in today's economy and society requires high levels of literacy, which must deal with a globalized and technologically advanced world, where the integrated global economy, growing intercultural migration, and technological advancement create an interesting alphabetical juxtaposition, in which individuals appear to be continually solicited. Therefore, managing the future literacy needs of individuals by different education systems becomes a difficult task due to the fact that the traditional literacy skills of the past are no longer sufficient to reach new goals. Alongside traditional literacy skills, new forms of literacy have emerged (technological, media literacy, and information literacy, which are indispensable for living and growing as citizens of the 21st century. At a time when information is rapidly and readily available, literacy of basic skills includes the ability to identify, select, evaluate, and synthesize large amounts of information (Goldin \& Katz, 2008). Furthermore, as communication between different cultures becomes more common, new literacy standards become more common. focus on communication skills and promote a deep understanding of other perspectives and cultures.

Thus, recent educational reforms do not always manage to keep up with the changes and reflect the problems that new alphabetic forms bring with them. Unfortunately, the reading of school results in Italy is not very exciting and shows how dangerous it is I know not to satisfy the achievement of curricular 
objectives at every school grade. If there is still a large and growing body of research supporting the idea that students enter school with different literacy skills and that these skills are the strongest predictor of later outcomes, i.e. that there is a strong relationship between previous outcomes and the subsequent ones, regardless of when they are recorded, then there can only be predictions about who will be pushed towards subsequent nefarious outcomes. If the initial disadvantage or advantage still morphs into a cumulative disadvantage or advantage today as strong pupils become more skilled and weaker pupils in difficulty continue to struggle with weaknesses and languish in uncomfortable situations, then the school continues to be effective only for those who do not need it. Therefore, although the idea of cumulative advantage exists in different dimensions and on several levels, the achievement of adequate "alphabetic states", originally conceptualized in results as effects, becomes a central goal in the efforts made by the school. The effects hypothesize that there are not only alphabetic differences in results at the beginning of formal education but that the gap between the able and the less able is already present and widens over time creating a loop from which it is difficult to escape: the able-bodied enter a virtuous cycle that accelerates their ability and those with poor ability are caught in a vicious circle that hinders their growth. A century after these claims and the emergence of scientific pedagogy, it is difficult to accept that this can still be produced and reproduced incessantly.

\subsection{Socio-economic status, literacy and acquisition processes}

It tries to look here at a problematic vision of the deficit that allows a reading of the student's culture of origin as a resource, in order to be used positively for the student's alphabetic development rather than being conceived as inadequate and, sometimes, even refusing. When disadvantaged children are argued to have fewer material resources, fewer educational books and toys, fewer opportunities to enhance the learning process (Bradley \& Corwyn, 2002; Brooks-Gunn \& Duncan, 1997), as well as a less languagecompatible linguistic background of the school, only reinforces the idea that these resources can affect students' ability to develop skills central to their existence, good relationships with teachers and peers, and so on. The focus on the deficit to be filled in to be understood in this paper as a problem above all in terms of pre-requisites and not only on that of a discriminating school capable of reproducing differences that derive from belonging to less well-off social classes (Bourdieu, 1979; Bourdieu \& Passeron, 1964a; 1964b; 1970; Bowles \& Gintis, 1976; Collins, 1977; Epstein, 2001). The attention to alphabetical prerequisites leads, on the contrary, not to represent the school as a place of a conservative force, which reproduces social inequalities, as a "factory of inequalities" (Perrenoud), but as a tool for innovation, positive growth, and construction cultural and social. Common to these explanations is the emphasis placed on the fact that children who have greater difficulties in adapting to the culture and needs of the school must be helped to support their learning path and not be left alone to walk the path that leads them. it leads to the achievement of educational or rewarded objectives only when they respond or behave according to the culture and values of the school. It is a question here of allowing them to understand, and better evaluate, the meaning that education assumes in their life to the point of increasing their motivation towards culture, inducing them to improve the quality of their performance and their relationships with peers and teachers and with the entire school community.

However, this does not mean intervening only on the cognitive level. There is no doubt that even on the level of social interactions, which can be considered exchange actions that permeate all cultural and social school phenomena, including group and inter-group processes and relationships within the class - conceived as wholes or joint results of voluntary and reward-induced individual actions (Blau, 1964; Coleman, 1990) - important acquisitions are played out. According to Blau 1964, the starting assumption is that people establish social relationships because they expect them to be rewarding and this implies that exchange is defined within a mechanism of social relations that does not depend on the rules that prescribe obligations. In line with this, exchanges and relationships within the classrooms must however be reciprocal in order to be sustainable and characterized by mutual stimuli and responses. If the interaction were not reciprocal it would be interrupted, as in the case of students who showed that they had common interests, such as in sports and other hobbies, and who through them were able to promote friendships then abandoned for a change of perspective. and interests. Therefore, students with greater difficulties in sustaining the reciprocity necessary to establish friendship and affiliation in school may have greater difficulties in the didactic context. Therefore, cognitive difficulties could add up and also be related to social competence, which is fundamentally important for making friends. Larsson and Frisk (1999) have 
suggested that poor social competence may increase the risk of being excluded from the peer group and being bullied. His study, based on interviews with children between the ages of 11 and 13, showed that those excluded from the peer group were perceived as those who, failing to gain social acceptance among peers, did not deserve the same respect. of the children who were included. This is in line with substantial evidence showing how aggressive children may be rejected by their peers (Coie, Dodge, \& Kupersmidt, 1990), as aggression and disruption are the characteristics most related to peer rejection and dislike in primary schools, as well documented in observational studies (Coie, Dodge, \& Kupersmidt, 1990).

In line with Homan (1961), Blau (1964), and Coleman, 1990), social interactions between students and teachers can be conceived as exchanging actions that lead teachers to perceive students more or less positively (McLoyd, 1997; 1998). There are groups of students with cultural disadvantages whose outcomes generally worsen as risk factors build up in life (Garmezy \& Masten, 1994; Masten \& Wright, 1997), such as those who are orphaned and cared for or placed in foster care, children of parents with alcohol or drug problems, children of refugees or belonging to ethnic minority groups, or in general who re in particularly vulnerable situations. This could expose them to bias, making it more difficult for them to develop relationships with peers (Attar, Guerra \& Tolan, 1994; Dodge, Pettit, \& Bates, 1994) and hinder the development of friendships with peers (Haugland, 2003), influencing the time of completion of school assignments, the outcomes, and relationships with teachers and classmates, even in terms of cultural differences, can complicate communication with teachers and peers at school (Berry et al., 2002; Brislin, 1981). The school context can be a particularly critical factor for the cultural and psychosocial development of the most vulnerable children due to their experience of additional risk factors.

Research has shown that teacher and peers support of the learning process may be particularly important for these individuals (Bru, Murberg, \& Stephens, 2001; Masten, Best, \& Garmezy, 1990), as it may also counteract difficult situations in which children with a history of problematic relationships with their parents may have developed a representative pattern of relationships that reduces their chances of building supportive relationships with teachers and peers (Pianta et al., 2002). It is therefore assumed those vulnerable children could be exposed to greater problems of social inclusion than others, also due to the fact that having fewer opportunities available and fewer resources, they could be affected by a greater distance from the school culture of other students and be more exposed to forms of prejudice. The effects related to these circumstances can make these students less open to social and cultural interaction and more exposed to further difficulties. But despite the many claims regarding the fact that the school's central mission is to ensure the literacy success of all pupils, our school system still remains not fully capable of ensuring full schooling and high quality for all pupils: the unconvincing and unjust results demonstrate this and the regularity with which difficulties are produced shows the product of a society that is increasingly unequal and unable to offer a high level of education to everyone.

\section{CONCLUSION}

In conclusion, the school cannot be transformed into a democratic space if it continues to be a "factory of illiteracy", where the relationship of students with knowledge is played out in the relationship between previous learning, difficulties, and the lack of psycho-emotional-cognitive learning. In this context, illiteracy becomes, in part and only in part, the reflection of inequalities of all kinds and, at the same time, the main factor of its strengthening. Therefore, training must make possible the mechanisms through which illiteracy occurs, the acceptance of the dominant culture, and the non-stigmatization of students; at the same time, it must meet the needs of all students who want and have the right to access better literacy management and to participate in a better social and cultural life. This approach works on the relationship between cognitive, affective, and psychomotor prerequisites and oneself, the others, knowledge, the world, which sees the process of equality aimed at developing the power of didactic action. The aim is to guarantee an emancipatory and reflexive learning process aimed at acquiring increasingly wider competencies. It is, therefore, necessary to examine, through wide-ranging research, the picture of risk factors that may negatively influence the general well-being of the individual, focusing on the importance assumed by the various compensatory forms, conceived as protective factors. The aim is to avoid the accumulation of various difficulties when entering the path of education, which, in time, may become stratified, turning into a deficit and later on into a "reserve population". The importance of the risk of being exposed to an accumulated deficit in school environments leads to the need to reflect on the adverse cultural and social 
conditions in order to take them into consideration in the elaboration of a quality educational proposal and in the creation of favorable conditions for learning. Therefore, it becomes urgent to focus explicitly on the contextual cultural factors and processes that can configure the accumulated deficit and the alphabetic disadvantage in an early stage, in order to avoid their incessant reproduction, even in an intergenerational sense. In this contribution, therefore, it was considered essential to highlight these relationships in-depth in order to better understand the nature of accumulated deficits, which are perpetuated over time in education and risk undermining students' acquisition processes, their well-being, and their future.

If the objective of the contribution was, therefore, to provide a brief overview of how social conditions and cultural characteristics can configure the risk of failure and influence the general well-being of the individual, focusing on the importance that the cumulative deficit assumes in relation to the teachinglearning processes, in the future the research intends to examine the possibility of elaborating a metaanalysis capable of reconstructing a conceptual framework of these factors, which is able to provide the weight that the various variables assume in the literature. The perspectives of the research refer, from the point of view of the prevention of the interventions to the analysis of the accumulated deficits as possible factors of risk of cultural and social exclusion. This interpretative framework is fundamental, also in reference to the interconnection with other alphabetic problems.

Finally, it is possible, therefore, to affirm that in order to get out of the relationships dominated by the dominant ones and from any form of oppression and exclusion, it is necessary to put equality at the center of the educational path without denying the differences, but tenaciously pursuing the alphabetic objectives of "becoming equal" with means and instruments. This does not mean, in education, denying social power relations, but recognizing them in order to face them through compensatory intervention linked to the construction of the conditions of academic and professional success. Only in this way can the equality of the human person be placed at the base of the school, which sees all individuals in a situation of equal access to all the symbolic universes and which forces education to renounce the authority to take sides in favor of individualization. of strategic devices capable of guaranteeing trust and support for learning, instead of omission or negligence.

\section{Conflict of interest}

No potential conflict of interest is reported by the authors.

\section{Funding}

No financial assistance from parties outside this article

\section{Acknowledgment}

N/A

\section{REFERENCES}

Attar, B., Guerra, N., \& Tolan, P. (1994). Neighborhood disadvantages, stressful life events and adjustment in urban elementary-school children. Journal of Clinical Child Psychology, 23(4), 391-400. https://doi.org/10.1207/ s15374424jccp2304_5

Bakken, A. (2003). Minoritetsspråklig ungdom i skolen: reproduksjon av ulikhet eller sosial mobilitet? [Minority-language youth in school: reproduction of dissimilarity or mobility? in Norwegian]. Norsk institutt for forskning om oppvekst.

Berry, J. W., Poortinga, Y. H., Segall, M. H., \& Dasen, P. R. (2002). Cross-cultural psychology: research and applications. Cambridge University Press.

Blau, P. M. (1964). Exchange and power in social life. Wiley.

Booth, T., \& Ainscow, M. (1998). From them to us: an international study of inclusion in education. Routledge.

Bourdieu, P. (1979). La distinction. Critique sociale du Jugement. Minuit.

Bourdieu, P., \& Passeron, J. (1964a). Les héritiers. Minuit.

Bourdieu, P., \& Passeron, J. (1964b). Les étudiants et leurs études. Mouton. 
Bourdieu, P., \& Passeron, J. (1970). La reproduction. Eléments pour une théorie du système d'enseignement. Minuit.

Bowles, S., \& Gintis, H. (1976). Schooling in capitalist America: educational reform and the contradictions of economics life. Basic Books.

Bradley, R. H., \& Corwyn, R. F. (2002). Socio-economic status and child development. Annual Review of Psychology, 53(1), 371-399. https://doi.org/10.1146/annurev.psych.53.100901.135233

Brislin, R. W. (1981). Cross-cultural encounters: face to face interaction. Allyn and Bacon.

Bronfenbrenner, U. (1995). Developmental ecology through space and time: a future percpective. In P. Moen, G. J. Elder \& K. Luscher (Ed.), Examining lives in context: perspectives on the ecology of human development (pp. 619648). American Psychological Association.

Brooks-Gunn, J., \& Duncan, G. J. (1997). The effects of poverty on children. Future Child, 7(2), 55-71. http://dx.doi. org/10.2307/1602387

Bru, E., Boyesen, M., Munthe, E., \& Roland, E. (1998). Perceived social support at school and emotional and musculoskeletal complaints among Norwegian 8th grade students. Scandinavian Journal of Educational Research, 42(4), 339-356. https://doi.org/10.1080/0031383980420402

Bryant, D., Burchinal, M., Lau, L., \& Sparling, J. (1994). Family and classroom correlates of Head Start children's development outcomes. Early Child, 9(3-4), 289-309. https://doi.org/10.1016/0885-2006(94)90011-6

Bursuck, W. D., \& Asher, S. R. (1986). The relationship between social competence and achievement in elementary school children. Journal of Clinical Psychology, 15(1), 41-49. https://doi.org/10.1207/s15374424jccp1501_5

Chatterji, M. (2006). Reading achievement gaps, correlates, and moderators of early reading achievement: evidence from the Early Childhood Longitudinal Study (ECLS) kindergarten to first grade sample. Journal of Educational Psychology, 98(3), 489-507. https://doi.org/10.1037/0022-0663.98.3.489

Claparede, E. (1920). L'école sur mesure. Libraire Payot

Coie, J. D., Dodge, K., \& Kupersmidt, J. B. (Eds.) (1990). Peer group behavior and social status. Cambridge University Press.

Coleman, J. (1990). Foundations of social theory. Belknap Press of Harvard University Press.

Coleman, J., Campbell, E., Hobson, C., McPartland, J., et al. (1966). Equality of educational opportunity. US Government Printing Office.

Collins, R. (1977). Functional and conflict theories of educational stratification. In, A. H. J. Karabel (Ed.), Power and ideology in education (pp. 118-136). Oxford University Press.

Croll, P. (2004). Families, social capital, and educational outcomes. British Journal of Educational Studies, 52(4), 390416. https://doi.org/10.1111/j.1467-8527.2004.00275.x

Crystal S., \& Shea D. (2003). Cumulative advantage, public policy, and late-life inequality. In S. Crystal, D. Shea, (Eds.), Economic outcomes in later life: public policy, health, and cumulative advantage (pp. 1-13). Springer.

Crystal, S., \& Shea, D. (1990). Cumulative advantage, cumulative disadvantage, and inequality among elderly people. The Gerontologist, 30(4), 437-443. https://doi.org/10.1093/geront/30.4.437

Crystal, S., Shea, D. G., \& Reyes, A. M. (2017). Cumulative advantage, cumulative disadvantage, and evolving patterns of late-life inequality. Gerontologist, 57(5), 910-920. https://doi.org/10.1093/geront/gnw056

Dean, J. (1989). Special needs in the secondary school: the whole school approach. Routledge.

Dodge, K., Pettit, G., \& Bates, J. (1994). Socialization mediators of the relation between socio-economic status and child conduct problems. Child Development, 65(2), 649-665. https://doi.org/10.2307/1131407

Duncan, G. J., \& Magnuson, K. (2011). The nature and impact of early achievement skills, attention skills, and behavior problems. In G. J. Duncan \& R. J. Murnane (Eds.), Whither opportunity? Rising inequality, schools, and children's life chances (pp. 47-89). Russell Sage Foundation.

Duncan, G. J., Dowsett, C. J., Claessens, A., Magnuson, K., et al. (2007). School readiness and later achievement. Developmental Psychology, 43(6), 1428-1446. https://doi.org/10.1037/0012-1649.43.6.1428

Dyson, A. (1999). Inclusion and inclusions: theories and discourses in inclusive education. In H. Daniels \& P. Garner (Eds.), Inclusive education: world yearbook of education (pp. 36-53). Kogan Page.

Epstein, J. (2001). School, family, and community partnerships: preparing educators and improving schools. Westview Press. Freire, P. (1970). La pedagogia degli oppressi. Mondadori

Garmezy, N., \& Masten, A. (1994). Chronic adversities. In, L. H. M. Rutter \& E. Taylor (Eds.). Child and adolescent 
psychiatry (pp. 191-208). Blackwell.

Giroux, H. (1987). Introduction: literacy and the pedagogy of political empowerment. In P. Freire \& D. Macedo (Eds.), Literacy: reading the word and the world (pp. 1-28). Routledge.

Goldin, C., \& Katz, L. (2008). The race between education and technology. Belknap Press for Harvard University Press.

Haug, P. (1998). Integration and special education research in Norway. International Journal of Education Research, 29(2), 119-130. https://doi.org/10.1016/So883-0355(98)00018-4

Haugland, B. S. M. (2003). Parental alcohol abuse: family functioning and child adjustment. University of Bergen.

Heath, S. B. (1983). Ways with words: language, life and work in communities and classrooms. Cambridge University Press.

Homan, G.C. (1961). Social behavior: Its elementary forms. Hardcourt, Brace \& World.

Jaffee, S. R., Caspi, A., Moffitt, T. E., Polo-Tomas, M., \& Taylor, A. (2007). Individual, family, and neighborhood factors distinguish resilient from non-resilient maltreated children: a cumulative stressors model. Child Abuse and Neglect, 31(3), 231-253. https://doi.org/10.1016/j.chiabu.2006.03.011

Kerlinger, F., \& Lee, H. (2000). Foundation of behavioral research (4th ed.). Harcourt College Publishers.

Krieger, N., Williams, D., \& Moss, N. (1997). Measuring social class in US public health research: methodologies and guidelines. Annual Review of Public Health, 18(1), 341-378. https://www.annualreviews.org/doi/pdf/10.1146/ annurev.publhealth.18.1.341

Kupersmidt, J., Coie, J., \& Dodge, K. (1990). Peer rejection in childhood. Cambridge University Press.

Larsson, B., \& Frisk, M. (1999). Social competence and emotional/behaviour problems in 6-16 year old Swedish school children. European Child \& Adolescent Psychiatry, 8(1), 24-33. https://doi.org/10.1007/s007870050080

Masten, A. S., \& Wright, M. O. D. (1997). Cumulative risk and protection models of child maltreatment. B. B. R. Rossman \& M. S. Rosenberg (Eds.), Multiple victimization of children: conceptual, developmental, research, and treatment issues (pp. 7-30). Haworth Press.

Masten, A. S., Best, K. M., \& Garmezy, N. (1990). Resilience and development: contributions from the study of children who overcome adversity. Development \& Psychopathology, 2(4), 425-444. https://doi.org/10.1017/ So954579400005812

McLoyd, V. (1997). The impact of poverty and low socio-economic status on the socio-emotional functioning of African-American children and adolescents: mediating effects. In R. D. Taylor \& M. Wang, Social and emotional adjustment and family relations in ethnic minority families (pp. 7-34). Erlbaum.

McLoyd, V. (1998). Socio-economic disadvantage and child development. American Psychologist, 53(2), 185 -204. https://doi.apa.org/doi/10.1037/0003-066X.53.2.185

Muthén, L. K., \& Muthén, B. O. (2004). Mplus: the comprehensive modeling program for applied researchers. Muthén \& Muthén.

Nordhagen, R., Nielsen, A., Stigum, H., \& Køhler, L. (2005). Parental reported bullying among Nordic children: a population-based study. Child: Care, Health \& Development, 31(6), 693-701. https://pubmed.ncbi.nlm.nih. gov/16207227/

Nuzzaci, A. (2016). Scienza dell'insegnamento, formazione e competenze metodologiche degli insegnanti e dei formatori: dalla progettazione alla valutazione. [Promoting and supporting the methodological skills of teachers and trainers for the successful of the teaching and the quality of the training]. Formazione \& Insegnamento. European Journal of Research on Education and Teaching, 14(3), 17-36. https://ojs.pensamultimedia. it/index.php/siref/article/view/2036

Nuzzaci, A. (2020). When "knowing how to read texts" means understanding and inferring meanings. Brolly. Journal of Social Sciences. 3(1), 7-39. https://www.journals.lapub.co.uk/index.php/brolly/article/view/1448/1199

Nuzzaci, A., \& Marcozzi, I. (2019). Fattori di rischio scolastici e dropout nella percezione degli studenti: il progetto internazionale ERASMUS KA2 ACCESS [School risk factors and dropout in students' perception: the international ERASMUS KA2 ACCESS project]. Giornale Italiano della Ricerca Educativa - Italian Journal of Educational Research, 12(23), 48-68. https://doi.org/10.7346/SIRD-022019-P48

Nuzzaci, A., \& Marcozzi, I. (2019). Leggere e comprendere testi e inferire significati - Reading and understanding texts and inferring meanings. In A. Nuzzaci (Eds.), Pedagogia, didattica e ricerca educativa: approcci, problemi e strumenti / [Pedagogy, teaching and educational research: approaches, problems and tools] (pp. 375-403). Pensa MultiMedia s.r.l.

Nuzzaci, A., \& Marcozzi, I. (2020). L'abbandono scolastico nella percezione degli studenti: un focus del progetto ACCESS / Early school leaving in students' perception: focus on the ACCESS Project. In SIRD, SIPES, SIREM, 
SIEMeS, Le Società per la società: ricerca, scenari, emergenze (Tomo 1, pp. 127-137). Pensa MultiMedia Editore s.r.l.

Pianta, R., Hamre, B., \& Stuhlman, M. (2002). Relationships between teachers and children. In, W. Reynolds \& G. Miller, Handbook of psychology. Educational psychology (pp. 199-234). Wiley.

Resnick, D. P., \& Resnick, L. B. (1977). The nature of literacy: an historical exploration. Harvard Educational Review, $47(3), 370-385$

Ross, C., \& Mirowsky, J. (2011). The interaction of personal and parental education on health. Social Science and Medicine, 72(4), 591-599. https://doi.org/10.1016/j.socscimed.2010.11.028

Senechal, M. (2006). Testing the home literacy model: parent involvement in kindergarten is differentially related to grade 4 reading comprehension, fluency, spelling and reading for pleasure. Scientific Studies of Reading, 10(1), 59-87. https://doi.org/10.1207/s1532799xssr1001_4

Senechal, M. (2011). A model of the concurrent and longitudinal relations between home literacy and child outcomes. In S. B. Neuman \& D. K. Dickinson (Eds.), Handbook of early literacy research (pp. 175-188). The Guilford Press.

Senechal, M., \& LeFevre, J.-A. (2002). Parental involvement in the development of children's reading skill: a five-year longitudinal study. Child Development, 73(2), 445-460. https://pubmed.ncbi.nlm.nih.gov/11949902/

Stanovich, K. E. (1986). Matthew effects in reading: some consequences of individual differences in the acquisition of literacy. Reading Research Quarterly, 21(4), 360-407. https://www.readingrockets.org/articles/ researchbytopic/4862

Stipek, J., \& Ryan, R. (1997). Economically disadvantaged preschoolers: ready to learn but further to go. Developmental Psychology, 33(4), 209-223. https://doi.org/10.1037/0012-1649.33.4.711

Storch, S. A., \& Whitehurst, G. J. (2001). The role of family and home in the literacy development of children from low-income backgrounds. In P. R. Britto \& J. Brooks-Gunn (Eds.), New directions for child and adolescent development. The role of family literacy environments in promoting young children's emerging literacy skills (pp. 5371). S Jossey-Bass/Pfeiffer.

Taylor, D., \& Dorsey-Gaines, C. (1988). Growing up literate: learning from inner-city families. Heinemann.

Welsh, M., Parke, R., Widaman, K., \& O’Neil, R. (2001). Linkages between children's social and academic competence: a longitudinal analysis. Journal of School Psychology, 39(6), 463-481. https://doi.org/10.1016/Soo224405(01)00084-X

Wentzel, K. (1993). Does being good make the grade? Social behavior and academic competence in middle school. Journal of Educational Psychology, 85(2), 357-364. https://doi.org/10.1037/0022-0663.85.2.357

Willis, P. (1977). Learning to labour: how working-class kids get working-class jobs. Saxon House.

Xue, Y., \& Meisels, S. J. (2004). Early literacy instruction and learning in kindergarten: evidence from the early childhood longitudinal study: kindergarten class of 1998-1999. American Educational Research Journal, 41(1), 191-229. https://doi.org/10.3102/00028312041001191

\section{AUTHOR}

Antonella Nuzzaci. Associate Professor of Experimental Pedagogy, Department of Human Studies, University of L'Aquila

\section{Conflict of interest}

No potential conflict of interest is reported by the author.

\section{Funding}

No financial assistance from parties outside this article.

\section{Acknowledgment}

